\title{
Prognostic value of 5-fluorouracil metabolic enzyme genes in Dukes' stage $B$ and $C$ colorectal cancer patients treated with oral 5-fluorouracil-based adjuvant chemotherapy
}

\author{
HIDEKI YAMADA, HISAE IINUMA and TOSHIAKI WATANABE \\ Department of Surgery, Teikyo University School of Medicine, Tokyo, Japan
}

Received August 6, 2007; Accepted October 3, 2007

\begin{abstract}
Fluorouracil (5-FU) is the most commonly used anticancer drug for colorectal cancer (CRC). In this study, we aimed to clarify the prognostic value of the expression of the 5-FU metabolic enzyme genes, including orptate phosphoribosyl transferase (OPRT), dihydropyrimidine dehydrogenase (DPD), thymidylate synthetase (TS) and thymidylate phosphorylate (TP) genes in CRC patients treated with oral 5-FU-based adjuvant chemotherapy. We examined 103 CRC patients with Dukes' stage B and C who underwent oral 5-FU-based adjuvant chemotherapy. Formalin-fixed, paraffin-embedded tumor specimens from primary CRC tissues were dissected by laser-captured microdissection and quantification of mRNA levels of OPRT, DPD, TS and TP were measured by real-time reverse transcription (RT) PCR. The relationship between these 5-FU metabolic enzyme gene levels and disease-free and overall survival rates were examined. The disease-free and overall survival curves of the OPRT mRNA high-expression group were significantly longer than that of the OPRT mRNA low-expression group. The disease-free and overall survival curves of the DPD mRNA high-expression group were significantly shorter than that of the DPD mRNA low-expression group. In contrast, there were no significant differences between the TS or TP mRNA highexpression and low-expression groups in the disease-free and overall survival curves. In a multivariate Cox regression analysis, it was demonstrated that the OPRT mRNA level is an independent prognostic variable for disease-free and
\end{abstract}

Correspondence to: Dr Hisae Iinuma, Department of Surgery, Teikyo University School of Medicine, 2-11-1 Kaga, Itabashi-ku, Tokyo 173-0003, Japan

E-mail: iinuma@med.teikyo-u.ac.jp

Abbreviations: CRC, colorectal cancer; 5-FU, 5-fluorouracil; OPRT, orotate phosphoribosyl transferase; DPD, dihydropyrimidine dehydrogenase; TS, thymidylate synthase; TP, thymidylate phosphorylate

Key words: colorectal cancer, 5-fluorouracil, orotate phosphoribosyl transferase, dihydropyrimidine dehydrogenase, thymidylate synthase, thymidylate phosphorylate overall survival. These results suggest that the OPRT mRNA is a useful indicator in the prediction of disease-free and overall survival in Dukes' B and C stage CRC patients treated with oral 5-FU-based adjuvant chemotherapy.

\section{Introduction}

Colorectal cancer (CRC) is one of the most common malignancies and 5-fluorouracil (5-FU) is widely used as a first-line of adjuvant chemotherapy in patients with CRC $(1,2)$. In western countries, adjuvant chemotherapy such as 5-FU plus leucovorin (LV) (5-FU/LV), infusional 5-FU, LV and oxaliplatin (FOLFOX) has been established as a generalized regimen for CRC patients undergoing curative resection $(3,4)$. In Japan, an oral form of the 5-FU-related drug such as Tegaful plus Uracil, doxifluridine (5'-DFUR) was developed for convenient administration and has been widely used in adjuvant chemotherapy for CRC $(5,6)$. However, the clinical effectiveness of oral 5-FU-based chemotherapy differs among patients (7). In designing optimal individualized adjuvant treatment, it is essential to predict the response to 5-FU and prognosis in each patient.

It is known that several 5-FU-related metabolic pathway enzymes are correlated with sensitivity to 5-FU (8-12). The antitumor effect of 5-FU is found in the inhibitor element of thymidylate synthase (TS), an essential DNA synthetic enzyme, by 5-fluoro-2'-deoxyuridine-5'-monophosphate (FdUMP) and the incorporation of 5-FU metabolites into RNA and DNA (8). The initial metabolism of 5-FU into nucleotides is essential for its action by one or more of the following pathways: directly to 5-fluorouridine-5'-monophosphate (FUMP) by orotate phosphoribosyl transferase (OPRT); indirectly to FUMP in a sequence of reactions with conversion of 5-FU to 5-fluorouridine phosphorylated by uridine phsophorylase (UP); indirectly to FdUMP by 2'-deoxy5-fluorouridine (FUdR) catalyzed by thymidine phosphorylase (TP) $(9,10)$. Furthermore, it is known that 5-FU is categorized to 2-fluoro- $\beta$-alanine in the liver and other tissues by dihydropyrimidine dehydrogenase (DPD) $(8,11,12)$. However, the prognostic value of these 5-FU-related metabolic enzymes in patients treated with 5-FU-based adjuvant chemotherapy is still controversial. It has been reported that a high-expression level of TS and low-expression levels of DPD were correlated with poor prognosis $(13,14)$. In contrast, it has been reported that OPRT, though not TS and DPD have a prognostic value in 
patients treated with 5-FU-based adjuvant chemo-therapy (15). It was thought that one of the reasons for these confused results is the purity of tumor samples. To resolve this problem, the present study used a laser microdissection system in order to enhance the purification of the colorectal tumor specimens.

In this study, using the real-time RT-PCR followed by sampling used by a laser microdissection, we evaluated the prognostic value of these 5-FU-related metabolic pathway genes in CRC patients with Dukes' stage B and C who were treated with oral 5-FU-based adjuvant therapy.

\section{Patients and methods}

Patients and treatment. One hundred and three CRC patients with Dukes' stage $\mathrm{B}$ and $\mathrm{C}$ who underwent complete resection of CRC without preoperative chemotherapy between 1995 and 2005 were enrolled. The average age of the patients was $63 \pm 15$ years (range, 31 to 80 ; median 66). The average follow-up time was $34 \pm 18$ months (range 4-60; median 30). This study was approved by the Ethics Committee of Teikyo University and each patient provided written informed consent. These patients were treated with oral 5-FU-based adjuvant chemotherapy. The patients received oral Tegaful plus Uracil (300 mg/m²/day) (UFT: Taiho Pharmaceutical Co. Ltd., Tokyo, Japan) or Tegaful, Uracil plus LV (75 mg/day) for a minimum of 1 year. The development of local recurrence, distant metastases, and death were re-evaluated in each patient. The evaluation consisted of the pertinent medical history, physical examination and repetition of imaging studies, including a CT scan of the abdomen.

Microdissection of tumor specimen. A representative formalin-fixed, paraffin-embedded tumor specimen was selected after examination of the hematoxylin and eosin stained slides. Ten micron thick sections were stained with neutral fast red to enable visualization of histology for laser capture microdissection (P.A.L.M. Microlaser Technologies AG, Munich, Germany), which was performed in order to ensure that only tumor cells were studied.

RNA extraction and cDNA synthesis. RNA was isolated from formalin-fixed, paraffin-embedded specimens using the MasterPure Purification kit (Epicenter, Madison, WI). After RNA isolation, cDNA was derived from each sample according to a previously described procedure (16).

Real-time quantitative reverse transcription-polymerase chain reaction $(R T-P C R)$. As target genes, OPRT, DPD, TS and TP mRNA were examined and $\beta$-actin mRNA was used as an internal control. Sequences of primers and probes are described in Table I. Target cDNA sequences were amplified by quantitative PCR using a fluorescence-based real-time detection method (ABI 7000, Perkin Ermer Co., USA) as described previously (17). In brief, the $25 \mu 1 \mathrm{PCR}$ reaction mixture contained $600 \mathrm{nmol} / \mathrm{l} \mathrm{dUTP}, 5.5 \mathrm{mmol} / \mathrm{l} \mathrm{MgCle}$ and Taq Man buffer A containing a reference dye. The PCR conditions were $50^{\circ} \mathrm{C}$ for $10 \mathrm{sec}$ and $95^{\circ} \mathrm{C}$ for $10 \mathrm{~min}$, followed by 42 cycles at $95^{\circ} \mathrm{C}$ for $15 \mathrm{sec}$ and $60^{\circ} \mathrm{C}$ for $1 \mathrm{~min}$. The levels of OPRT, DPD, TS and TP mRNA were normalized by $ß-$
Table I. Sequence of primers and probes.

\begin{tabular}{lll}
\hline Primer / Probe & Sequence \\
\hline OPRT & F & TAGTGTTTGGAACTGTTGAGGTT \\
& R & CTTGCCTCCCTGCTCTCTGT \\
& Probe & 6FAM-TGGCATCAGTGACCTTCAAGCCCTCCT \\
DPD & F & AGGACGCAAGGAGGGTTTG \\
& R & GTCCGCCGAGTCCTTTACTGA \\
& Probe & 6FAM-CAGTGCCTACAGTCTCGAGTCTGCCAGTG \\
TS & F & GCCTCGGTGTGCCTTCA \\
& R & CCCGTGATGTGCGCAAT \\
& Probe & 6FAM-TCGCCAGCTACGCCCTGCTCA \\
TP & F & CCTGCGGACGGAATCCT \\
& R & GCTGTGATGAGTGGCAGGCT \\
& Probe & 6FAM-CAGCCAGAGATGTGACAGCCACCGT \\
B-actin & F & TGAGCGCGGCTACAGCTT \\
& R & TCCTTAATGTCACGCACGATTT \\
& Probe & 6FAM-ACCACCACGGCCGAGCGG \\
\hline
\end{tabular}

actin mRNA. All evaluations of data were performed without knowledge of the clinical status of the patients and controls.

Statistical analysis. The correlation between the mRNA levels and clinicopathological parameters were evaluated using the Fisher's exact test and the Chi-squared test. The Student's t-test was used to compare the dose of Tegaful between the 5-FUrelated mRNA high-expression and low-expression groups. The disease-free survival time and overall survival time were examined according to the Kaplan-Meier survival curve and the statistical significance was calculated using the log-rank test. The Cox proportional-hazards regression analysis was used to estimate univariate and multivariate hazard ratios for disease-free survival and overall survival. A $p<0.05$ was regarded as statistically significant.

\section{Results}

Comparison of administered dose of 5-FU. The levels of OPRT, DPD, TS and TP mRNA were normalized by B-actin mRNA. The patients were divided into a 5-FU metabolic enzyme mRNA high-expression group and a low-expression group with a cut-off value. The cut-off values obtained by median levels were 1.33 for OPRT (range, 0.60-3.53), 0.67 for DPD (range, 0.17-2.70), 1.58 for TS (range, 0.60-3.80) and 2.71 for TP (range, 0.41-7.17) mRNA.

Table II shows the comparison of the dose of Tegaful in the mRNA high-expression and low-expression groups of OPRT, DPD, TS or TP genes. It was shown that a total dose of Tegaful did not result in any significant differences between the high-expression and low-expression groups.

Clinicopathological features versus TS, DPD, OPRT and TP $m R N A$ levels. The relationship between OPRT, DPD, TS and TP gene expressions and the clinicopathological factors were examined (Table III). No statistically significant differences in 
Table II. Comparison of a total dose of Tegaful (g) in the high-expression and low-expression groups of 5-FU metabolic enzyme genes.

\begin{tabular}{lccc}
\hline mRNA & OPRT mRNA & DPD mRNA & TS mRNA \\
\hline High-expression group & $196 \pm 112$ & $220 \pm 276$ & $213 \pm 190$ \\
Low-expression group & $224 \pm 254$ & $200 \pm 289$ & $235 \pm 245$ \\
\hline
\end{tabular}

Table III. The relationship of clinicopathological factors and OPRT, DPD, TS, TP mRNA levels.

\begin{tabular}{|c|c|c|c|c|c|c|c|c|}
\hline \multirow{2}{*}{ Variables } & \multicolumn{2}{|c|}{ OPRT } & \multicolumn{2}{|c|}{ DPD } & \multicolumn{2}{|c|}{ TS } & \multicolumn{2}{|c|}{$\mathrm{TP}$} \\
\hline & $\begin{array}{c}\text { High } \\
(n=66)\end{array}$ & $\begin{array}{c}\text { Low } \\
(n=37)\end{array}$ & $\begin{array}{l}\text { High } \\
(\mathrm{n}=46)\end{array}$ & $\begin{array}{c}\text { Low } \\
(n=57)\end{array}$ & $\begin{array}{l}\text { High } \\
(n=54)\end{array}$ & $\begin{array}{c}\text { Low } \\
(n=49)\end{array}$ & $\begin{array}{l}\text { High } \\
(n=51)\end{array}$ & $\begin{array}{c}\text { Low } \\
(n=52)\end{array}$ \\
\hline \multicolumn{9}{|l|}{ Tumor size } \\
\hline$<5 \mathrm{~cm}$ & $35(53.0)$ & $15(40.5)$ & $23(50.0)$ & $27(47.4)$ & $26(48.2)$ & $24(49.0)$ & $25(49.2)$ & $25(48.1)$ \\
\hline$\geq 5 \mathrm{~cm}$ & & $\mathrm{p}=0.30$ & & $\mathrm{p}=0.79$ & & $\mathrm{p}=1.00$ & & $\mathrm{p}=1.00$ \\
\hline \multicolumn{9}{|l|}{ Histological type } \\
\hline (Well) & $49(74.2)$ & $24(64.9)$ & $31(67.4)$ & $42(73.7)$ & $37(68.5)$ & $36(73.5)$ & $38(74.5)$ & $35(67.3)$ \\
\hline \multirow[t]{2}{*}{ (Moderate, Poor, Muc) } & $17(25.8)$ & $13(35.1)$ & $15(32.6)$ & $15(26.3)$ & $17(31.5)$ & $13(26.5)$ & $13(25.5)$ & $17(32.7)$ \\
\hline & & $\mathrm{p}=0.37$ & & $\mathrm{p}=0.52$ & & $\mathrm{p}=0.67$ & & $\mathrm{p}=0.52$ \\
\hline$(-)$ & $63(95.5)$ & $31(83.8)$ & $39(84.8)$ & $55(96.5)$ & $50(92.6)$ & $44(89.8)$ & $49(96.1)$ & 45 (85.6) \\
\hline \multirow[t]{2}{*}{$(+)$} & $3(4.6)$ & $6(16.2)$ & $7(15.2)$ & $2(3.5)$ & $4(7.4)$ & $5(10.2)$ & $2(3.9)$ & $7(13.5)$ \\
\hline & & $\mathrm{p}=0.07$ & & $\mathrm{p}=0.07$ & & $\mathrm{p}=0.73$ & & $\mathrm{p}=0.16$ \\
\hline \multicolumn{9}{|l|}{ Lymphatic invasion } \\
\hline$(-)$ & $41(62.1)$ & $24(64.9)$ & $27(58.7)$ & $38(66.7)$ & $37(68.5)$ & $28(57.1)$ & $29(58.9)$ & $36(69.2)$ \\
\hline \multirow[t]{2}{*}{$(+)$} & $25(37.9)$ & $13(35.1)$ & $19(41.3)$ & $19(33.3)$ & $17(31.5)$ & $21(42.9)$ & $22(43.13)$ & $16(30.8)$ \\
\hline & & $\mathrm{p}=0.83$ & & $\mathrm{p}=0.42$ & & $\mathrm{p}=0.31$ & & $\mathrm{p}=0.22$ \\
\hline \multicolumn{9}{|l|}{ Venous invasion } \\
\hline$(-)$ & $32(48.5)$ & $18(48.7)$ & $22(47.8)$ & $28(49.1)$ & $27(50.0)$ & $23(46.9)$ & $27(53.9)$ & $23(44.2)$ \\
\hline \multirow[t]{2}{*}{$(+)$} & $34(51.5)$ & $19(51.4)$ & $24(52.2)$ & $29(50.9)$ & $27(50.0)$ & $26(53.1)$ & $24(47.1)$ & $29(55.8)$ \\
\hline & & $\mathrm{p}=1.00$ & & $\mathrm{p}=1.00$ & & $\mathrm{p}=0.84$ & & $\mathrm{p}=0.43$ \\
\hline \multirow[t]{2}{*}{$(+)$} & $29(43.9)$ & $22(59.5)$ & $26(56.5)$ & $25(43.7)$ & $26(48.2)$ & $25(51.0)$ & $26(51.0)$ & $25(48.1)$ \\
\hline & & $\mathrm{p}=0.15$ & & $\mathrm{p}=0.24$ & & $\mathrm{p}=0.84$ & & $\mathrm{p}=0.43$ \\
\hline
\end{tabular}

clinicopathological factors were observed between these metabolic genes in the high-expression and low-expression groups.

Survival versus OPRT, DPD, TS and TP mRNA levels. Kaplan-Meier disease-free and survival curves of CRC patients were examined between the levels of 5-FU metabolic enzyme mRNA high-expression and low-expression groups. Disease-free survival was analyzed for patients with a curative resection (Fig. 1). In this analysis, the high-OPRT mRNA groups showed a significantly longer survival as compared with that of the low-OPRT mRNA group. Furthermore, patients who were in the high-DPD mRNA expression group showed a significantly shorter survival time than those in the low-DPD mRNA group. In contrast, the disease-free survival in the high-expression groups of TS or TP mRNA did not show any significant differences compared with that of the low-expression group. Overall survival curves were analyzed for all patients as shown in Fig. 2. The OPRT high-expression groups showed a significantly longer survival as compared with that of the OPRT low-expression group. The DPD high-expression group showed a significantly shorter survival rate than that of the DPD low-expression group. In contrast, TS or TP mRNA did not show any significant differences between the high-expression and the low-expression groups.

Univariate and multivariate analysis of OPRT, DPD, TS and $T P$ mRNA levels as predictors of survival. We conducted a univariate and multivariate Cox proportional hazard regression 
(A) OPRT

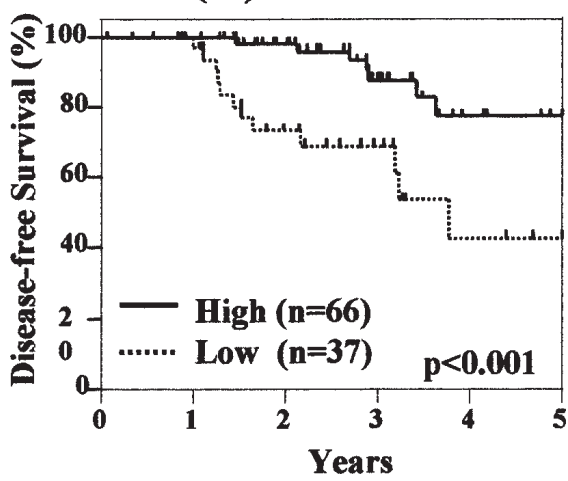

(C) TS

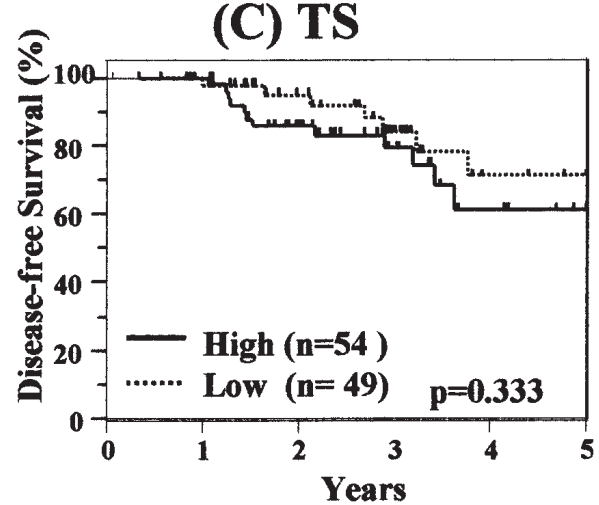

(B) DPD

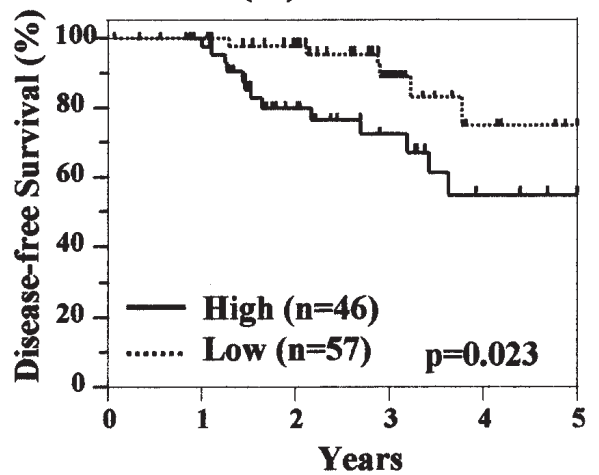

(D) $\mathrm{TP}$

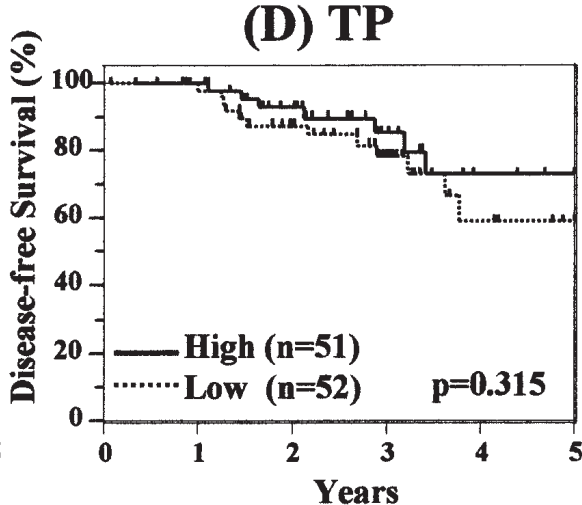

Figure 1. Disease-free survival analysis based on the expression of 5-FU metabolic enzyme genes. Disease-free survivals of OPRT mRNA (A), DPD mRNA (B), TS mRNA (C) and TP mRNA (D) were analyzed by the Kaplan-Meier method. Significant differences were shown between the high-expression and lowexpression groups in OPRT mRNA and DPD mRNA.

(A) OPRT

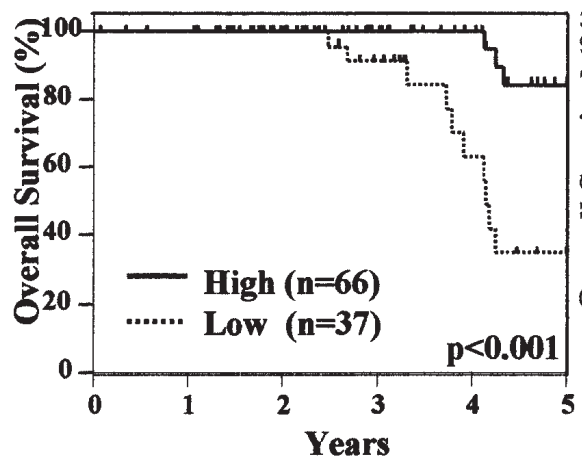

(C) TS

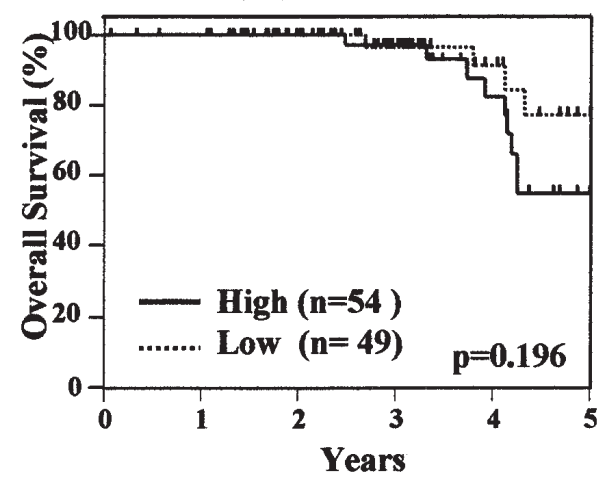

(B) DPD

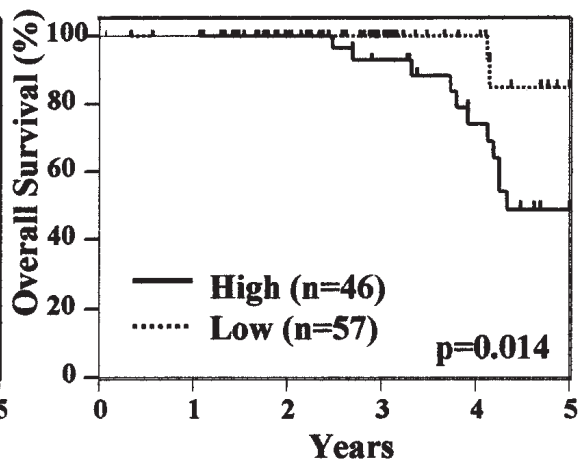

(D) TP

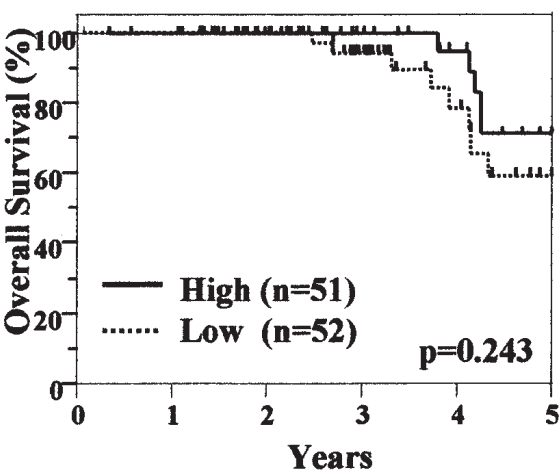

Figure 2. Overall survival analysis based on the expression of 5-FU metabolic enzyme genes. Overall survival of OPRT mRNA (A), DPD mRNA (B), TS mRNA (C) and TP mRNA (D) were analyzed by the Kaplan-Meier method. Significant differences were shown between the high-expression and low-expression groups in OPRT mRNA and DPD mRNA. 
Table IV. Cox regression analysis for disease-free survival.

\begin{tabular}{|c|c|c|c|c|}
\hline \multirow[t]{2}{*}{ Variables } & \multicolumn{2}{|c|}{ Univariate Analysis } & \multicolumn{2}{|c|}{ Multivariate Analysis } \\
\hline & $\begin{array}{l}\text { Hazard Ratio } \\
(95 \% \mathrm{CI})\end{array}$ & P-value & $\begin{array}{l}\text { Hazard Ratio } \\
(95 \% \mathrm{CI})\end{array}$ & P-value \\
\hline Tumor size & $1.37(0.87-2.25)$ & 0.18 & - & \\
\hline Histological type & $1.46(0.92-2.30)$ & 0.11 & - & \\
\hline Depth of invasion & $2.72(1.52-4.52)$ & 0.02 & $1.43(0.76-2.55)$ & 0.25 \\
\hline Lymphatic invasion & $1.40(0.89-2.23)$ & 0.14 & & \\
\hline Venous invasion & $2.29(1.32-4.75)$ & 0.002 & $1.85(1.04-3.90)$ & 0.03 \\
\hline Lymph node metastasis & $2.64(1.52-5.48)$ & 0.001 & $2.17(1.22-4.56)$ & 0.007 \\
\hline OPRT & $0.48(0.29-0.76)$ & 0.002 & $0.60(0.35-0.99)$ & 0.04 \\
\hline DPD & $1.71(1.07-2.89)$ & 0.02 & $1.29(0.77-2.29)$ & 0.33 \\
\hline TS & $1.26(0.79-2.06)$ & 033 & - & \\
\hline TP & $0.79(0.48-1.24)$ & 0.31 & - & \\
\hline
\end{tabular}

Table V. Cox regression analysis for overall survival.

\begin{tabular}{|c|c|c|c|c|}
\hline \multirow[t]{2}{*}{ Variables } & \multicolumn{2}{|c|}{ Univariate Analysis } & \multicolumn{2}{|c|}{ Multivariate Analysis } \\
\hline & $\begin{array}{l}\text { Hazard Ratio } \\
(95 \% \mathrm{CI})\end{array}$ & P-value & $\begin{array}{l}\text { Hazard Ratio } \\
(95 \% \mathrm{CI})\end{array}$ & $\mathrm{P}$-value \\
\hline Tumor size & $1.62(0.92-3.10)$ & 0.09 & - & \\
\hline Histological type & $1.34(0.76-2.33)$ & 0.29 & - & \\
\hline Depth of invasion & $2.05(1.12-3.58)$ & 0.02 & $1.18(0.62-2.12)$ & 0.58 \\
\hline Lymphatic invasion & $1.19(0.689-2.10)$ & 0.52 & - & \\
\hline Venous invasion & $1.82(1.00-3.85)$ & 0.04 & $1.36(0.71-3.07)$ & 0.36 \\
\hline Lymph node metastasis & $3.43(1.52-14.63)$ & 0.001 & $2.38(0.89-10.78)$ & 0.08 \\
\hline OPRT & $0.36(0.17-0.64)$ & 0.001 & $0.48(0.21-0.93)$ & 0.03 \\
\hline DPD & $2.31(1.19-5.89)$ & 0.01 & $1.43(0.67-3.80)$ & 0.37 \\
\hline TS & $1.45(0.84-2.80)$ & 0.19 & - & \\
\hline TP & $0.72(0.39-1.25)$ & 0.25 & - & \\
\hline
\end{tabular}

analysis for disease-free survival (Table IV). In a univariate analysis, depth of invasion, venous invasion, lymph node metastasis, OPRT mRNA and DPD mRNA showed a significant association for disease-free and overall survival. A Cox multivariate analysis was performed for factors that showed a significance in a univariate analysis and venous invasion, lymph node metastasis and OPRT mRNA showed a significant correlation for disease-free survival.

We then examined univariate and multivariate Cox proportional hazard regression analysis for overall survival (Table V). In a univariate analysis, depth of invasion, venous invasion, lymph node metastasis, OPRT mRNA and DPD mRNA showed a significant association for overall survival. A Cox multivariate analysis was performed for factors that showed a significance in a univariate analysis and OPRT mRNA showed a significant correlation for overall survival.

These results suggest that the OPRT mRNA expression levels could be a useful prognostic indicator for disease-free and overall survival of CRC patients with Dukes' stage B and $\mathrm{C}$ who are treated with adjuvant chemotherapy based on 5-FU oral administration.

\section{Discussion}

In this study, we showed that the OPRT mRNA level makes it possible to predict a prognosis in Dukes' B and C stage CRC patients treated with oral 5-FU-based adjuvant chemotherapy.

As to the methodology of 5-FU metabolic pathway enzymes, protein activity, immunohistochemistry, enzymelinked immunosorbent assay (ELISA) and mRNA levels have been reported (13-15). Concerning the routine measurement of these enzymes, protein activity measurements are not technically feasible because of the complexity in the use of radioisotopes. In contrast, the real-time RT-PCR method is reproducible, simple, rapid and suitable for use even with very small amounts of tumor tissues such as a biopsy. Furthermore, it has been thought that inaccurate results occur when the surrounding normal tissues are contaminated in tumor samples. To resolve this problem, we introduced a laser microdissection system in combination with real-time RT-PCR.

Several molecular markers associated with 5-FU metabolic pathway enzymes such as OPRT, DPD, TS and TP have been examined for prediction of the prognosis in CRC patients 
treated with 5-FU-based chemotherapy (13-15,18-22). In our study, all patients were treated with Tegafur-Uracil combination therapy. It is known that Tegaful is converted to 5-FU, which kills cancer cells and Uracil inhibits degradation of the relased 5-FU.

OPRT is anticipated to play a key role in the first step, leading to DNA synthesis inhibition and RNA dysfunction. Recently, using the enzyme activity method though not mRNA, Ochiai et al reported that patients with high levels of OPRT activity have a longer survival outcome than individuals with low levels (15). Ichikawa et al reported that the survival time of patients with a high OPRT/DPD ratio is significantly longer than that of patients with a low OPRT/DPD ratio in metastatic CRC-treated with 5-FU-based chemotherapy (23). In this study, using the real-time RT-PCR followed by sampling used by laser microdissection, we demonstrated that the disease-free and overall survival times of the OPRT mRNA high-expression group were significantly longer than that of the low-OPRT mRNA group. Furthermore, in the multivariate Cox regression analysis, we demonstrated that the OPRT mRNA level is an independent prognostic value for disease-free survival and overall survival. To the best of our knowledge, our paper is the first study that demonstrates the prognostic value of OPRT mRNA of tumor cells in Dukes' stage $\mathrm{B}$ and $\mathrm{C}$ patients treated with 5-FU-based oral adjuvant chemotherapy.

DPD is a rate-limiting enzyme released during the catabolism of 5-FU. In a previous study, it was reported that high DPD mRNA levels affect the acquisition of resistance to 5-FU (24). Many reports show that patients with low-DPD levels have a better prognosis to 5-FU than those with highDPD levels $(14,25)$. In our Kaplan-Meier survival curve analysis, the low-DPD mRNA group showed a significantly longer survival time than those in the high-DPD mRNA group. In the Cox univariate analysis, our study demonstrated that the DPD mRNA expression in tumors was related to survival. In a multivariate analysis, however, DPD mRNA level did not show an independent prognostic value. Ichikawa et al reported that the DPD gene expression had no predictive value for survival supporting our results (24).

The prognostic value of TS in colorectal cancer patients also appears to be controversial. Several studies have reported that TS levels predict an overall outcome for patients in the early stages of CRC $(26,27)$. Elder et al reported that patients whose tumors expressed the highest expression of TS had a significantly longer disease-free survival if they were treated with adjuvant therapy compared with surgery (28). In contrast, in the present study, it was difficult to predict the efficacy of TS mRNA levels for prognosis. This discrepancy might be explained by the differences in the treatment schedule and drugs based on 5-FU such as Tegaful, UFT, 5'-DFUR and TS-1. In our study, we treated the Dukes' B or C patients with oral administration of Tegaful and Uraci or UFT, Uracil plus LV.

It is known that TP has activity as an angiogenesisinducing factor and as a metabolic enzyme for the fluoropyrimidines. The prognostic significance of TP mRNA expression in CRC is still unclear. Nishimura et al reported that the prognosis of high TP groups is better than that of low TP groups (29). Salonga et al reported that TP together with high levels of TS are reported to be associated with a poor response to 5-FU (30). In the present study, however, TP mRNA did not show a prognostic value for disease-free survival and overall survival.

In this study, we have shown that the OPRT mRNA level is useful for the prediction of a prognosis in Dukes' B and C stage CRC patients treated with oral 5-FU-based adjuvant chemotherapy. The information of the OPRT gene appears to be a promising approach for optimal individualized adjuvant treatment.

\section{Acknowledgements}

We appreciate Dr K. Okinaga and Dr T. Takada for their critical comments, and thank Ms. J. Tamura for her technical work. We also thank Taiho Pharmaceutical Co. Ltd. Japan for their support.

\section{References}

1. Moertel CG: Chemotherapy for colorectal cancer. N Engl J Med 330: 1136-1143, 1994.

2. Soros GA, Grogan LM and Allera CJ: Preclinical and clinical aspects of biomodulation of 5-fluorouracil. Cancer Treat Rev 20: 11-49, 1994

3. Andre T, Boni C, Mounedji-Boudiat L, et al: Oxaliplatin, fluorouracil and leucovorin as adjuvant treatment for colon cancer. N Eng J Med 350: 2343-2351, 2004

4. Hobday TJ: An overview of approaches to adjuvant therapy for colorectal cancer in the United States. Clin Colorectal Cancer S11-18, 2005.

5. Sakamoto J, Hamada C, Kodaira S, Nakazato H and Ohashi Y: Ajuvant therapy with oral fluoropyrimidines as main chemotherapeutic agents after curative resection for colorectal cancer: individual patients data meta-analysis of randomized trials. Jpn J Clin Oncol 29: 78-86, 1999.

6. Sakamoto J: Efficacy of oral adjuvant therapy after resection of colorectal cancer: 5-year results from three randomized trials. J Clin Oncol 22: 484-492, 2004

7. Hafstrom L, Rudenstam C-M and Domellof L: Swedish gastrointestinal tumor adjuvant therapy group: A randomized trial of oral 5-fluorouracil versus placebo as adjuvant therapy in colorectal cancer Dukes' B and C: results after 5 years observation time. Br J Surg 72: 138-141, 1985.

8. Longley DB, Harkin DP and Johnston PG: 5-fluorouracil: mechanisms of action and clinical strategies. Nat Rev Cancer 3: 330-338, 2003.

9. Peters GJ, van Groeningen CJ, Laurensse EJ and Pinedo HM: A comparison of 5-fluorouracil metabolism in human colorectal cancer and colon mucosa. Cancer 68: 1903-1909, 1991.

10. Maring JG, Groen HJ, Wachters FM, Uges DR and de Vries EG: Genetic factors influencing pyrimidine-antagonist chemotherapy. Pharmacogenomics J 5: 226-243, 2005.

11. Diasio RB and Johnson MR: The role of pharmacogenetics and pharmacogemonics in cancer chemotherapy with 5-fluorouracil. Pharmacology 61: 199-203, 2000.

12. van Kuilenburg AB: Dihydropyrimidine dehydrogenase and the efficacy and toxicity of 5-fluorouracil. Eur J Cancer 40: 939-950, 2004.

13. Ciaparrone M, Quirino M, Schinzari G, Zannoni G, Corsi DC, Vecchio FM, Cassano A, Torre G La and Barone C: Predictive role of thymidylate synthase, dihydropyrimidine dehydrogenase and thymidine phosphorylase expression in colorectal cancer patients receiving adjuvant 5-fluorouracil. Oncology 70: 366-377, 2006.

14. Kornmann M, Schwabe W, Sander S, et al: Thymidylate systhase and dihydropyrimidine dehydrogenase mRNA expression levels: Predictors for survival in colorectal cancer patients receiving adjuvant 5-fluorouracil. Clin Cancer Res 9: 4116-4124, 2003.

15. Ochiai T, Nishimura K, Noguchi H, Kitajima M, Tsukada A, Watanabe E, Nagaoka I and Futagawa S: Prognostic impact of orotate phosphribosyl transferase among 5-fluorouracil metabolic enzymes in respectable colorectal cancers treated by oral 5fluorouracil-based adjuvant chemotherapy. Int J Cancer 118: 3084-3088, 2006. 
16. Lord RV, Salonga D, Danenberg KD, et al: Telomerase reverse transcriptase expression is increased early in the Barrett's metaplasia, dysplasia, carcinoma sequence. J Gastrointest Surg 4: $135-142,2000$.

17. Gibson UE, Geid CA and Williams PM: A novel method for real-time quantitative RT-PCR. Genome Res 6: 995-1011, 1996.

18. Terashima M, Fujiwara H, Takagine A, et al: Role of thymidine phosphorylase and dihydropyrimidine dehydrogenase in tumour progression and sensitivity to doxifluridine in gastric cancer patients. Eur J Cancer 38: 2375-2381, 2002.

19. Fujii R, Seshimo A and Kameoka S: Relationships between the expression of thumidylate synthas, dihydropyrimidine dehydrogenase, and orotae phosphoribosyltransferase and cell proliferative activity and 5-fluorouracil sensitivity in colorectal carcinoma. Int J Clin Oncol 8: 72-78, 2003.

20. Isshi K, Sakuyama T, Gen T, Nakamura Y, Kuroda T, Katuyama T and Maekawa Y: Predicting 5-FU sensitivity using human colorectal cancer specimens: comparison of tumor dihydropyrimidine dehydrogenase and orotase phosphoribosyl transferase activities with in vitro chemosensitivity to 5-FU. Int J Clin Oncol 7: 335-342, 2002.

21. Kinoshita M, Kodera Y, Hibi K, Nakayama G, Inoue T, Ohashi N, Ito Y, et al: Gene expression profile of 5-fluorouracil metabolic enzymes in primary colorectal cancer: potential as predictive parameters for response to fluorouracil-based chemotherapy. Anticancer Res 27: 851-856, 2007.

22. Fukushima M, Murakami Y, Suzuki N and Aib K: The analysis of the innate pathways of 5-fluorouracil phosphorylation in human gastrointestinal cancer cell lines in vitro and in vivo. Oncol Rep 4: 1189-1194, 1997.

23. Ichikawa W, Uetake H, Shirota Y, Yamada H and Takahashi T: Both gene expression for orotate phosphoribosyltransferase and its ratio to dihydropyrimidine dehydrogenase influence outcome following fluoropyrimidine dehydrogenase influence outcome following fluoropyrimidine-based chemotherapy for metastaic colorectal cancer. Br J Cancer 89: 1486-1492, 2003.
24. Uetake H, Ichikawa W, Takechi T, Fukushima M, Nihei Z and Sugihara K: Relationship between intratumoral dihydropyrimidine dehydrogenase activity and gene expression in human colorectal cancer. Clin Cancer Res 5: 2836-2839, 1999.

25. Ichikawa W, Uetake H, Sirota Y, Yamada H, Nishi N, Nihei Z, Sugihara K and Hirayama R: Combination of dihydropyrimidine dehydrogenase and thymidylate synthase gene expressions in primary tumors as predictive parameters for the efficacy of fluoropyrimidine-base chemotherapy for metastatic colorectal cancer. Clin Cancer Res 9: 786-791, 2003.

26. Leichman CG: Thymidine synthase as a predictor of response. Oncology 12: 43-47, 1998.

27. Findlay MP, Cumnigham A, Morgan G, Clinton S, Hardcastle A and Aheme GW: Lack of correlation between thymidylate synthase levels in primary colorectal tumors and subsequent response to chemotherapy. Br J Cancer 75: 903-909, 1997.

28. Elder D, Kressner U, Ragnhammar P, et al: Immunohistochemically detected thymidylate synthase in colorectal cancer: an independent prognostic factor of survival. Clin Cancer Res 6: 488-492, 2000.

29. Nishimura G, Terada I, Kobayashi T, et al: Thymidine phophrylase and dihydropyrimidine dehydrogenase levels in primary colorectal cancer show a relationship to clinical effects of 5'-deoxy-5-fluorouridine as adjuvant chemotherapy. Oncol Rep 9: 479-482, 2002.

30. Salonga D, Danenberg KD, Johnson M, Metzger R and Groshen S: Colorectal tumors responding to 5-fluorouracil have low gene expression levels of dihydropyimidine dehydrogenase, thymidine synthase, and thymidine phosphrylase. Clin Cancer Res 6: 1322-1327, 2000. 